\title{
Market and Value Chain Analyses of Marketable Natural Products from Agroforestry Systems in Eastern Sudan
}

\author{
Bashir A. El Tahir'1, Akshay Vishwanath ${ }^{2}$ \\ ${ }^{1}$ Freelance Consultant, Agroforestry and Ecosystems Analysis, El Obeid, Sudan \\ ${ }^{2}$ People and Landscapes Programme, Eastern and Southern Africa Regional Office (ESARO), International Union \\ for Conservation of Nature (IUCN), Nairobi, Kenya \\ Email: eltahirba48@gmail.com
}

Received 12 October 2015; accepted 27 November 2015; published 30 November 2015

Copyright ( 2015 by authors and Scientific Research Publishing Inc.

This work is licensed under the Creative Commons Attribution International License (CC BY). http://creativecommons.org/licenses/by/4.0/

(c) $\underset{\mathrm{EY}}{\mathrm{B}}$ Open Access

\section{Abstract}

The objectives of the present study were: 1 ) to identify the prioritized marketable natural products (NPs) from agroforestry systems (AFS), and 2) to conduct market value chain analyses of the most important and prioritized NPs to identify markets and marketing channels; actors, functions and characteristics; constraints and opportunities to entry and growth; opportunities for value addition, and conduct analysis of strengths, weaknesses, opportunities and threats (SWOT analysis). The study was conducted in the Refugees' camps and their hosting communities in Eastern Sudan. Using the participatory value chain analysis (PVCA) approach, it was found that communities in the project sites obtained a multiplicity of NPs for sustenance and for increasing their incomes. Eight products were identified and ranked as the most important NPs with greatest opportunities for enterprise development at the community level. These are: gum Arabic, honey, fodder, non-timber forest products (NTFPs) and tree seeds. Gum Arabic has been shown to score higher ranks in terms of a) marketability b) ecological suitability (availability), c) social suitability, and d) potential for value addition. The results show that marketing of gum Arabic in the study site is characterized by a large number of producers and relatively few traders and companies work through seven marketing channels. The results demonstrate that in the customary marketing channel there is an upward skewed benefit distribution among the value chain actors. The total relative commercialization margin was $80 \%$ indicating that "traders" accrued higher proportion, while "producers", receive less income (20\%) of the end market price. Poor land security, one-sided prices, taxes and levies, lack of finance and appropriate skills are major impediments to gum commodity growth and development. One of the most important opportunities for growth and entry of Gum Arabic are: it is natural organic product and thus well-fit for fair trade, environmentally sustainable and organic market development. Numerous opportunities exist in the site for value addition and distribution synergies and gender-specific development, including that gum 
Arabic has high synergy with natural resource management and other sectors for enhancing regional and national growth. The study concludes that Gum Arabic production and marketing is financially profitable for producers, traders and companies and has the potential to open new markets and bring new opportunities to smallholder farmers. However, technical, financial, and institutional support could result in an increase in local actors' income and contribute to sustainability of the supply of the product.

\section{Keywords}

Gum Arabic, Agroforestry Systems, Value Chain, Sudan, Natural Products

\section{Introduction}

The value chain describes the full range of activities which are required to bring a product or service from conception, through the different phases of production (involving a combination of physical transformation and the input of various producer services), delivery to final customers, and final disposal after use [1] [2]. The value chain concept embraces the idea of actors connected along a chain producing and bringing goods and services to end consumers through a complex and sequenced set of activities. This is a broader concept than "supply chain" that refers to the upstream enterprises providing inputs to a particular stage in a value chain [2] [3]. A value chain is different from the conventional analysis of a market place, because it does not only analyze the activities and degree to which firms in a chain operate, but also takes into account power relations and governance, and the effect these aspects have on actors in the chain [1].

Value chain analysis is based on a complete characterization of input-output relationships from grower to retailer, and the coordinating mechanisms that guide activities at each stage. It can include consideration of technical transformations of product, pricing, costs and margins, number and size of firms at each stage, barriers to entry, market power and the sharing of benefits from innovation, product differentiation and diversification [1] [4].

Value chain development has become a key approach in both research and policy fields, with an increasing number of bilateral and multilateral aid organizations adopting it to guide their development interventions [3] [5]-[8]. According to [5], poor agricultural producers often struggle to gain market access, because they lack knowledge of market requirements or the skills to meet them. Furthermore, poor information flow and other obstacles in value chains prevent them from entering into new markets, or reduce the benefits they obtained from entry. As a consequence, donor initiatives that foster value chain development, often with a focus on reducing poverty among smallholder farmers, are designed to overcome some of these obstacles [5] [6]. Often such initiatives try to mobilize the knowledge and resources of lead firms in value chains (such as retailers) to help poor producers as well as input and service providers to enter markets and add value [5].

Value chains analysis can be a participatory and empowering process [3] [5] [8]. Using maps and diagrams enables even poor and disadvantaged stakeholders to be involved in the collection and analysis of information. This promotes dialogue and responsibility between stakeholders as they analyze and negotiate their common interests in improving the functioning of chains and identifying those interventions likely to be most useful [5]. Participatory value chains analysis (PVCA) can highlight the constraints on those controlling the chain and clarify the possibilities for change lower down [7]-[9]. It can help overcome barriers and communicate the standpoints of those lower down the chain to those nearer the top. It can help make chains freer and fairer and redistribute benefits to those currently disadvantaged [5]. The value chain concept is generally based on five actions or events that are implemented in sequence, [3] namely: 1) selection of sector and value chains, 2) value chain mapping, 3) consultations with lead firms and other chain participants, 4) participatory value chain analysis 5) stakeholder validation and planning workshops.

In the center of the action is the participatory value chain analysis [10]. The tools and methods used need not be sequential, as there are activities that will probably be done in parallel (for example, maps and interviews to refine them), or will be revisited continuously as knowledge is being gained during the appraisal. Participatory analysis is one of the main rapid appraisal methods used in value chain analysis. Tools used during a participatory value chain analysis may include key informant interviews, focus groups, analysis of strengths, weaknesses, opportunities and threats (SWOT analysis), radar charts, scoring, checklists, questionnaires, participant observa- 
tion and use of appropriately skilled local community members as researchers [10].

For years, long-term participatory processes for improving natural resource management and exploring income generating options for rural communities in Eastern Sudan has long been the major concern of NGOs, regional and national authorities. Through participatory mapping and planning processes carried out by SRRLIL project rain-fed agroforestry systems and drylands natural products (NPs) have been identified as important assets to community livelihoods. Trade in the NPs from the AFS presents an opportunity to positively impact on the livelihoods of the communities as well as on the environment [8], and preserving land from degradation through erosion in the project sites. Despite their importance to local communities and that there are interested buyers for these commodities, there are no accurate information about their marketing and use.

The SRRLIL projectaims to explore strategies to strengthening the local capacity of the targeted communities in the project sites to trade successfully in NPs emanated from AFS systems supported by the project. The main focus was to develop sustainable NPs enterprises in the study sites that will be of benefit for the local inhabitants, to biodiversity and landscape. Since, the global market for NPs is growing rapidly; there is a need to create economic opportunities for poor rural communities in the project sites by linking them to market for the NPs. Furthermore, there is an urgent need for identifying prioritized NPs and their value chains so as to connect producers with market, supporting and linking up market players along the chain. To fill these gaps the objectives of this paper were to: identify priority marketable NPs accrued from AFS; conduct market and value chain analyses of one of the selected NPs to identify markets and marketing channels; actors, functions and characteristics; constraints and opportunities to entry and growth; opportunities for value addition, and conduct analysis of strengths, weaknesses, opportunities and threats (SWOT analysis).

\section{Material and Methods}

\subsection{Study Area}

Eastern Sudan comprises three States (the Red Sea, Kassala and Gedarif), and covers an area of 336,489 $\mathrm{km}^{2}$ with a population of 4.5 million people, that is $21 \%$ of the Sudan population. Over the past years, the region suffered from many circumstances that crippled its development including economic deterioration, drought and desertification cycles, food gaps and diseases. Eastern Sudan stands in an important strategic location and shares borders with four countries including Egypt in the north, Eritrea and Ethiopia on the east and Saudi Arabia across the Red Sea coast (Figure 1). The major livelihood style in Eastern Sudan are agriculture, consisting of traditional rain fed, mechanized rain fed, irrigated horticultural crops, animal husbandry and forest exploitation mainly in the form of gum tapping and woodcutting.

The project sites (Mefaza and Hawata) and (Kilo 26 and Shagarab) are located in Gedarif and Kassala states, respectively. Gedarif state lies between longitudes $33^{\circ} 34^{\prime \prime} \mathrm{E}$ and $37^{\circ} \mathrm{E}$ and latitudes $12^{\circ} 40^{\prime \prime} \mathrm{N}$ and $15^{\circ} 45^{\prime \prime} \mathrm{N}$ with an area of $71,000 \mathrm{~km}^{2}$ (16.9 million feddan)., while Kassala lies between latitudes $14^{\circ} 29 " \mathrm{~N}$ and $17^{\circ} 13 \mathrm{~N}$ and longitudes $34^{\circ} 13^{\prime \prime} \mathrm{E}$ and $37^{\circ} 02^{\prime \prime} \mathrm{E}$ with an area of about 72,000 $\mathrm{km}^{2}$. Around 6,500,000 feddan is dedicated to rain fed mechanized farming, 2,400,000 feddan for traditional farming and 187,250 feddan for irrigated farming. Agricultural productivity in Gedarif State remains low and does not meet the local demands, as agricultural outputs often vary from season to season. Existing technology transfer systems include the conventional approaches, such as the traditional teaching method (teacher to farmer), the technology transfer (trainer to farmer) and the participatory approach (farmer to farmer).

In Hawata the project works in two villages, Khalifa and Hai Al-Hijra villages with a population of 622 and 440 households, respectively. In Mefaza two villages are also covered by the project activities, these are Banat Sharej and Hemura with populations of 520 and 780 households respectively. According to the official documents (UNDP/UNHCR, 2011) about 5599 heads of households' refugees live in Shagarab' three camps. Shagarab camps lie at a distance of $23 \mathrm{Km}$, SE of Khashm El Girba town and belong to Wad Alhilaew Locality. The same documents tell us that about 2110 heads of households of refugees live in Kilo 26 camp. This camp lies to the NW of Khasm El Girba town at a distance of $19 \mathrm{Km}$. and falls within Khashm El Girba Locality.

Agriculture is the main occupation and farmers constitute over $90 \%$ in Mefaza and over $60 \%$ in Hawata [11]. However, varying proportions of farmers, both males and females, are also engaged in other occupations, mainly as officials, petty traders, casual workers, tea and coffee sellers and water fetchers. Generally, farms are small in the area with average households having a farm size of 5 feddans or less. Female-headed household have less farm land than male-headed households. The land is legally owned by the government and their right to it is only 


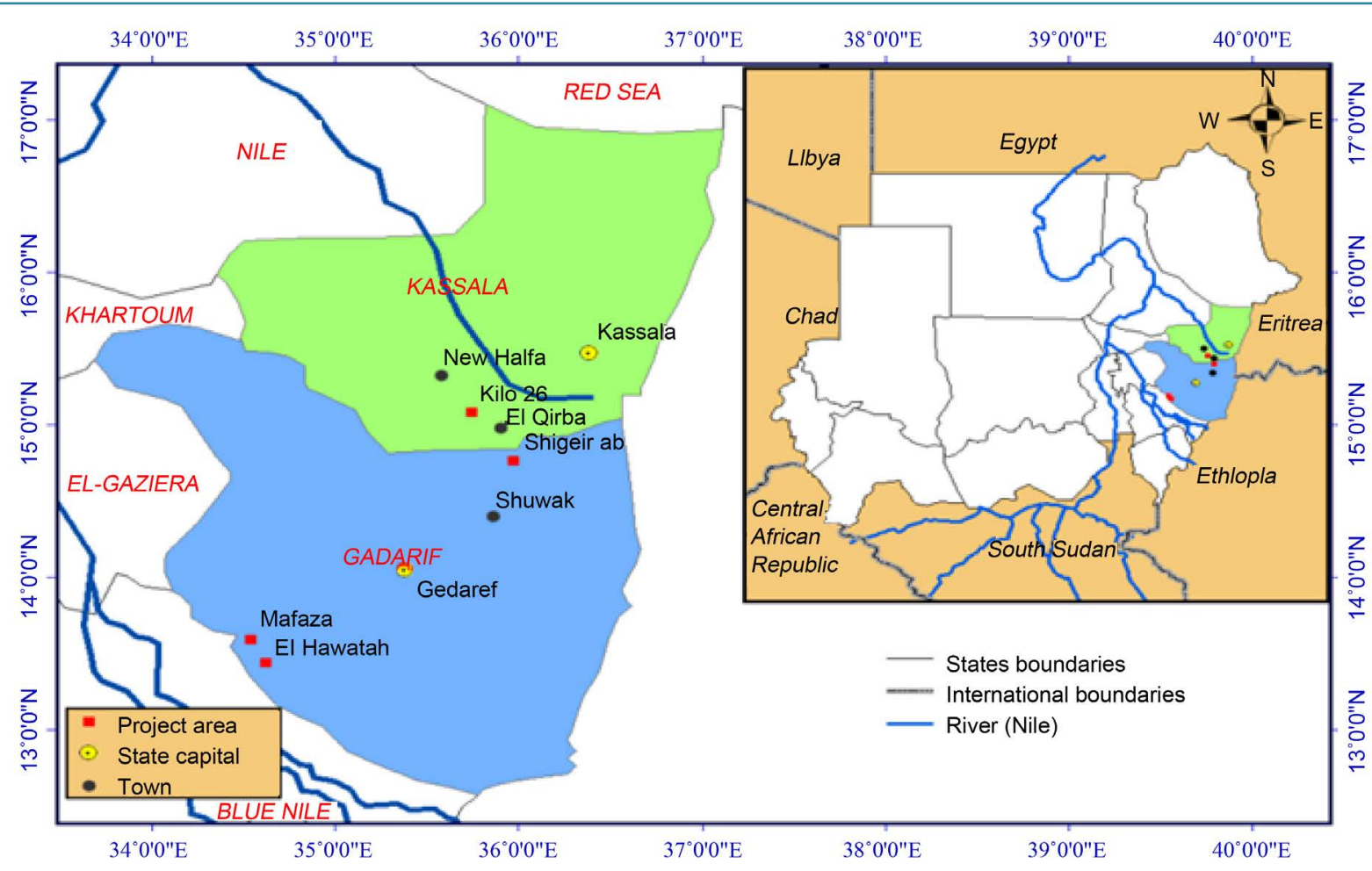

Figure 1. Locations of Gedarif and Kassala states and project sites.

usufructuary.

AFS in the project sites can be categorized into three main systems, namely the taungya; rain fed agroforestry and irrigated agroforestry. The three systems are most commonly practiced to provide livelihood benefits to local inhabitants and widely accepted by FNC for rehabilitation of the degraded forests. Although these land-use systems are distinct economic activities, farmers variously engage in other livelihood activities to supplements their income. For example, during off season farmers in the project sites seek employments or perform some sort of petty trading outside their residences. Moreover, farmers in the project sites rarely keep records of inputs, outputs and prices associated with these types of minor activities and this situation presents a challenge for the comprehensive collection of quality data about each land-use system.

The three AFS are: 1) Taungya system, is a forest management tool adopted by FNC to be implemented through the Participatory Forest Management (PFM) approach to rehabilitate degraded forests in the Eastern Region. The main objectives were to regenerate and protect reserved forest, while helping vulnerable landless men and women of local communities to earn a living on land under FNC ownership, 2) Rain fed agroforestry, is traditionally practiced by small farmers on communal lands in the study area. In these areas farmers cultivate sorghum and other cash crops with A. senegal. In the refugee camps at Shagarab, which fall outside the Acacia senegal ecological zone, households cultivate sorghum with Acacia seyal under taungya systems in the reserve forests, where annually FNC distribute 100 feddans for 50 families and 3) Irrigated agroforestry, practiced in Kilo 26 and was introduced as earlier as 1999 by the Women Committee, where it was basically carried out to meet the increasing demand for fire wood and as a source for fodder. The system is practiced on communal lands secured by UNHCR, IUCN and FNC. An area of 88 feddans was established, 50 feddans of which was allocated for the village, and the remaining 38 feddans were allocated for the refugees in the camp. The production systems are usually operated by smallholder farmers in an area of 30 feddan under irrigation. About 20 households each have 1.5 feddan to cultivate with agricultural crops according to their preference in strips between forest trees. The plots are fenced with barbed wire.

\subsection{Data Collection Methods and Analysis}

The data were collected during a field survey from 17-22 February, 2013. Both primary and secondary data were 
collected to complement each other. Primary data were gathered using the participatory value chain analysis (PVCA) approach. Participatory analysis is one of the main rapid appraisal methods used in value chain analysis, where information assembly and analysis are carried out largely by chain stakeholders with the support team acting as facilitators [10]. It is understood that with broader participation, solutions to value chain constraints are generally more appropriate to the local setting, and when stakeholders understand and take ownership of the value chain development process they are more likely to remain actively engaged beyond the life of the project [3] [7] [9] [10]. The essential information was collected using the following tools: focus group discussion, key informants, expert consultation, and analysis of strengths, weaknesses, opportunities and threats (SWOT analysis).

Focus groups discussion (FGD): In order to identify prioritized NPs for market and value chain analysis a group of 10 to 15 people from agroforestry farmers were organized irrespective of means of livelihoods, market access and ethnic compositions. This was done with the help of project officers and local people. The groups are made up of both male and female participants of different age and ethnic groups. Prior to discussion a checklist with a set of discussion topics was prepared to guide the FGD and the key informants'. The checklist aimed at generating relevant information on the prioritized NPs, availability, source and distribution, seasonal patterns, its importance, challenges and opportunities for production and marketing, barriers to entry into NPs trade, etc.; the potential for income generation, existing market situation and actors, market institutions and facilities, marketing problems and possible solutions, institutional capacity for market led development, credit facilities and constraints. A total of 4 focused group discussions (FGDs) were held through peer discussions, consultations and active participation. These stakeholders included a team of researchers, informed community members, local leaders and officials from FNC, private sector and NGOs.

Key informants interview (KIs): The data collection was made at community and institution (project sites and localities) levels. A total of 11 persons from different institutions and 50 persons from the communities in the four sites participated in providing information. Government institutions contacted at different levels of administration include: Federal and State Forests officials in Gedarif, Hawata, Mefaza; Project staffs at El Fau, Hawata, Mefaza, Kilo 26; Market authorities in Gedarif, the Deputy Director, the Agricultural Research Stations in El Fau. The non-government institutions included: Gum Arabic producers and traders in Hawata and Gedarif, the Gum Arabic Association in Gedarif; traditional honey producers and traders in Hawata, modern honey producers at El Fau. Others institutions that have some connections with the target groups and the prioritized NPs value chain included commercial banks in Hawata, Gedarif and Kassala. The project administration officers facilitated the discussions made with community level only. Theissues discussed included, but not limited to their functions and perspectives related to the production and marketing of the identified NPs, their sustainability as a development tool, the business senabling environments for marketing (national policies and regulations, organization of actors, potential for partnerships and capacity building).

The secondary data were collected from IUCN project documents and reports, range-wise reports, legal and policy documents, market reports, published literature, FNC reports, socio-economic and environmental conditions reports, agroforestry and traditional practice data, and socio-economic aspects of households in the study sites.

Data analyses were conducted by use of SPSS version 11.5 and Excel computer software programs. All the data collected were summarized and subjected to descriptive statistics involving computation of sums, means, and percentages.

\section{Results and Discussion}

\subsection{Selection of Prioritized NPs for Value Chain Analysis}

The selection of NPs for value chain analysis was conducted in consultation with local communities, using focus group discussion. The participants have identified the main direct use products (marketable) and indirect use services (non-marketable) originated from AFS. In this paper the focus will be on priority marketable NPs for value chain analysis.

The selection of value chain development was based on the following criteria: 1) economic importance of the products (marketability), 2) ecological suitability (availability) has been expressed in terms of adaptation of the products to the area adaptation to the sites, 3) social suitability, expressed as communities or farmers' willingness to engage in production and trading of the product, and 4) potential for adding local values to the products 
through improved processing and trading. Based on the findings of the assessment made during focus group discussion, the study team attached relative scores ranging from 1 (the lowest) to 5 (the highest) to each of the above criteria. Using the above criteria, participants (male and female) have been given equal chances to give scores from 1 to 5 to the most important marketable NPs in their areas. The highest average score was used to select NPs for value chain analysis.

The ranking result shows that gum Arabic and honey scored an average value of 4 - 5 (Table 1) and hence was selected for value chain analysis. The other commodities/activities given in Table 1 could be considered for interventions related to income generation activities (IGA). It is clear from the results that local communities use and appreciate the values of a variety of NPs derived from trees in AFS and natural resources such as gums, firewood, honey, NTFPs, fodder, medicinal plants, tree seeds from A. senegal, A. seyal and others species. The relevance of the value chain activities for the different communities in the project sites is given in Table 2 . The table shows that both gum Arabic and honey value chain were serviceable for Mefaza, Hawata and Shagarab sites, while honey value chain is suitable for the four sites.

\subsection{Value Chain of Gum Arabic in the Study Sites}

Gum Arabic is one of the major commercial non-timber forest products (NTFPs) in the Sudan traded locally and internationally. It is produced by tapping the bark of Acacia senegal and Acacia seyal trees. Gum Arabic is an important strategic commodity in Sudan. This natural product obtained from natural forests and plantations is

Table 1. Selection of NPs for value chain development in the study sites.

\begin{tabular}{lccccccc}
\hline & & \multicolumn{3}{c}{ Criteria for selection } & & \\
\cline { 2 - 7 } & Products & Marketability & Availability & $\begin{array}{c}\text { Producers } \\
\text { willingness }\end{array}$ & $\begin{array}{c}\text { Value } \\
\text { addition }\end{array}$ & $\begin{array}{c}\text { Total } \\
\text { score }\end{array}$ & $\begin{array}{c}\text { Average } \\
\text { scores }\end{array}$ \\
\hline $\mathbf{1}$ & Gum Arabic & 5 & 5 & 5 & 5 & 20 & 5 \\
$\mathbf{2}$ & Honey & 5 & 3 & 4 & 4 & 16 & 4 \\
$\mathbf{3}$ & Fodder & 4 & 3 & 3 & 2 & 12 & 3 \\
$\mathbf{4}$ & NTFPS & 4 & 3 & 2 & 2 & 11 & 3 \\
$\mathbf{5}$ & Fuel wood & 4 & 2 & 2 & 1 & 9 & 2 \\
$\mathbf{6}$ & Tree seeds & 4 & 3 & 3 & 1 & 11 & 3 \\
$\mathbf{7}$ & Medicinal plants & 4 & 2 & 2 & 2 & 10 & 4 \\
$\mathbf{8}$ & Dyes & 4 & 2 & 2 & 1 & 9 & 3 \\
$\mathbf{9}$ & Hand crafts & 4 & 2 & 2 & 1 & 9 \\
\hline
\end{tabular}

Table 2. Coverage of value chain and income generating activities.

\begin{tabular}{|c|c|c|c|c|c|}
\hline & \multirow{2}{*}{ NPs for value chain } & \multicolumn{4}{|c|}{ Project sites } \\
\hline & & Hawata & Mefaza & Shagarab & Kilo 26 \\
\hline 1 & Gum Arabic & $\mathrm{x}$ & $\mathrm{X}$ & $\mathrm{x}$ & \\
\hline 2 & Honey & $\mathrm{x}$ & $\mathrm{X}$ & $\mathrm{x}$ & $\mathrm{X}$ \\
\hline 3 & Fodder & $\mathrm{x}$ & $\mathrm{X}$ & $\mathrm{x}$ & \\
\hline 4 & NTFPS & $\mathbf{x}$ & $\mathbf{X}$ & $\mathbf{x}$ & $\mathbf{X}$ \\
\hline 5 & Fuel wood & $\mathrm{x}$ & $\mathrm{X}$ & & $\mathrm{X}$ \\
\hline 6 & Tree seeds & $\mathrm{x}$ & $\mathrm{X}$ & & $\mathrm{X}$ \\
\hline 7 & Medicinal plants & & $\mathrm{X}$ & & \\
\hline 8 & Dyes & $\mathrm{x}$ & $\mathrm{X}$ & & $\mathrm{X}$ \\
\hline 9 & Hand crafts & $\mathrm{x}$ & $\mathrm{X}$ & & $\mathrm{X}$ \\
\hline
\end{tabular}


being increasingly recognized for its role in rural livelihoods, biodiversity conservation and export values. In the past years several issues have characterized the commodity subsector. These include unsustainable supply, lack of transparency in marketing and marketing information and inequitable sharing of benefits among the participating groups, especially small farmers (producers) of the commodity.

Gum Arabic is a natural organic dried exudates produced from the trunk and branches of the A. senegal tree, known as "hashab" or hard gum, and the A. seyal tree, known as "Taleh" or flaky gum [12]. The gum is a pale white to orange brown solid which breaks with a glassy fracture, and is widely used in the food and pharmaceutical industry as an emulsifier, stabilizer, texturizer, film former and binder. "Acacia gum" as an item of trade dates back to the 17th century B.C. when it was traded by Arab traders who bought the gum from Sahelian West and Central Africa to Egypt and Europe.

Sudan is primarily the world's largest producer of gum Arabic; it contributes to about $95 \%$ of the total world gum Arabic production [13]. Sudan effectively controls almost over 80\% of the world market [13]-[15]. Gum Arabic provides an average of $12 \%$ of the gross domestic product (GDP) of the country. Gum production accounts for about $15.3 \%$ and $10 \%$ of the household income of gum producers and other farmers in the gum belt in Sudan, respectively [16] [17]. It was ascertained that gum production was economically more efficient and much less labor intensive compared to all other alternative cash crops [17]. As well, it was verified that gum Arabic as a product of small household farm system has a good comparative advantage and relatively higher international competitiveness in relation to other competing cash crops [16]. Gum production is characterized by a remarkable flexibility as a means for combating poverty as it provides insurance service against risks and uncertainties [18] [19].

\subsubsection{Resource Base, Production, Yield and Collection}

The gum belt in Sudan spans over two main distinct areas. Mainly the sandy soils in the west, consists of North and South Kordofan, the five Darfur states. The second is the central clay plain, which is formed by Kassala, Gedarif, Blue Nile and White Nile States. In Gedarif State, naturally growing gum producing trees have been subject to vast degradation due to wanton clearance for the expansion of the Mechanized Crop Production Schemes (MCPS) and traditional agriculture. In spite of that, gum producing tree species cover substantial areas of the State and also have vast areas that can be considered potentially suitable for planting gum Arabic trees for income generation as the state lies within the arid and semi-arid zones where gum trees naturally habituate.

Gum Arabic yields per tree are very variable. The average yield per tree varies from tree to tree, and can be affected by time and intensity of tapping and weather conditions. Good rainfall, followed by dry and hot weather conditions is conducive for obtaining good harvests. A yield of $250 \mathrm{~g} /$ tree per season is generally cited as average, but individual trees may yield up to $1 \mathrm{~kg}$. Yields from cultivated trees are said to increase up to the age of 15 years, when they level off and then begin to decline after 20 years. The highest yields are observed on individuals aged from 9 to 12 years. In general, the higher the average temperature the higher the yield of gum, while cold weather may reduce or even stop gum production. The production of gum Arabic from the trees starts by tapping the trees using the "Axes and "Harba". The gum oozes out and will be ready for collection after 4 - 6 weeks after tapping. Collection is usually by hands. Subsequent collections can be done bi-weekly, 5 to 6 pickings can be obtained from the same wound.

Gum is normally collected in baskets made from Doom or Date palm leaves and/or cloth bags, then packed in hessian sacks. It is recommended that gum should not be collected in plastic containers, because it makes gum clumpy with loose granulation, and discolored, hence reduce quality. After collection the producers then transport the gum to sell it either to village merchant, city merchants or sell directly in the gum auction market at Gedarif.

Gum tapping and collection are carried out by males from Kordofan States (Karddafa). These are historically skilled tappers. They normally rent gum gardens either from FNC or private sector or employed by gardens owners. The common rent for 10 feddan range from 25 to 40 SDG/feddan. In certain circumstances they work on sharecropping arrangement with some gardens owners. These collectors are in their economically active age and are highly experienced in gum collection. In the study sites gum tapping and collection is a male dominated activity. This is mainly attributed to the fact that gum tapping and collection is in remote sites and not suitable for women. Also, it was found that gum tapping skills are limited among the communities in the study sites. The preponderance of the middle age and young people in gum tapping and collection activities suggests that gum production requires active and young people who endure harsh environmental conditions at the production sites. 


\subsubsection{Post-Harvest Care, Processing and Grading}

Processing of gum Arabic is done to enhance the quality of the produce. At the producer levels gum Arabic for the primary or secondary markets get no processing prior to marketing apart from the removal of tree bark and plant debris. The produce destined for the terminal markets is put on pick-ups or Lorries and the loading and off-loading is done manually. Gum destined for export is, however, cleaned and sorted into different grades. This takes place in processing plants owned by the private sector.

There is one privately own gum processing company (El Refabi) in Gedarif town (Table 4) where gum processing is further cleaned to remove small plant debris and soils, then grading into different grades and gum powder. The processing plant employs women on temporary basis to clean and grade gum before packing for export or domestic market. The processing plant employs about 20 to 30 females. These females were generally poor and perform this job as an important income generating activities. The main reason for employing women in these activities is because they are diligent, patient and more enduring. Also male employees are present especially for loading and off-loading purposes and other activities.

As one of the key countries in gum Arabic production and marketing, Sudan has a well-established grading system for gum Arabic. The grading system provides an important reference point to determine the value of the harvested gum and provides the basis for proper pricing. There are 6 main grades and the most expensive grade is grades I which is hand-picked-selected or HPS (Selected Sorts); the cleanest, lightest color, uniformly shaped, medium sized nodules [14].

\subsubsection{Markets and Marketing Channels}

[20] define a market as the organized action between potential buyers (market demand) and potential sellers (market supply) that enables them to trade. A market is any established operating means or exchange for business dealings between buyers and sellers. Markets are characterized by buyers who demand goods or resources that produce them and suppliers who make products or resources available if the price is right. [21] defined local NTFPs markets to encompass immediate village markets, markets within neighboring villages and local towns, roadside, harbor or junction selling points, and markets in the nearest large urban centers and cities.

There are number of markets within the study area that are involved in marketing of gum Arabic and other agricultural products. According to [21] these can be categorized into primary market, secondary and terminal markets. Table 3 shows the main secondary and terminal markets and estimated number of traders. According to key informants the amounts of gum Arabic traded in these markets varies annually. Market trade peaks from December to March and drops during rainy season (October to January).

Primary markets usually consists of small, local markets with a high level of self-sufficiency of agricultural commodities that act as local exchange places as well as suppliers of the regional and national markets. Most sellers are producers and most buyers are consumers. Primary markets are usually located within a village market or near gum Arabic-producing villages. They have no physical infrastructure and market days are variable with some markets operating once or twice a week and others operating daily. Trading is by direct negotiation between sellers and buyers or sometimes through brokers.

Secondary markets consist of a group of medium-sized markets of regional importance, with a medium level of self sufficiency of supplies. These markets act as meeting points for the small local markets and as intermediate assembly points for the large urban markets. They have limited facilities and infrastructure (Marketing place) which are demarcated for selling marketed products. They are more secure and better managed than the primary markets. Government officials are present to collect taxes and royalties.

Table 3. Main gum Arabic markets in the eastern region.

\begin{tabular}{cccc}
\hline Markets & Categories & Number of traders \\
Gedarif & Terminal & $6-8$ \\
Galel Nahal & Secondary & $3-4$ \\
Hawata & Secondary & $3-4$ \\
Bazora & Secondary & $2-3$ \\
Doka & Secondary & $2-3$ \\
\hline
\end{tabular}


Terminal markets are big urban markets with infrastructure facilities such as information facilities, offices and telecommunication. Officials from the government authority and market management are present at the market. Products for export are inspected and certificates are issued by government officials from respected departments (Sudanese Standards and Metrology Corporation (SSMC), Taxes, FNC levies, Zakat).

The term "marketing" includes the performance of business activities that directs the flow of the products from producer to consumer or user. [22] defines the concept of marketing as "a set of activities by which the demand structure for goods, ideas and services is managed in order to facilitate the exchange process satisfactorily”. Marketing also implies knowledge that is at the disposal of producers to identify market opportunities in the form of market needs and wants, analyze competition, and develop appropriate approaches to reach the markets and to make profit. It uses a mixture of basic factors comprising products, channels of distribution, promotion and price by which it satisfies the needs and wants of the customers in the markets. Marketing operates in an environment that is created by economic, social, cultural, technological, political, regulatory, legal, institutional and infrastructural factors, all of which are beyond the control of the individual operators doing marketing [23] [24].

Generally, the supply chain of gum Arabic in the study area comprises five functional stages: 1) commodity base, 2) production (collection), 3) marketing, 4) processing, and 5) distribution (domestic or international). The supply chain is also linked to producers and consumers through a series of institutions (organizations, rules and regulations), technical assistance in terms of research findings, training, taxes and policy regulations, and related actors who provide services such as transportation, loading and off-loading laborers, labors at processing plants.

Marketing of gum Arabic in the study site is characterized by a large number of producers/collectors and relatively few traders and companies. The Gum Arabic marketing chain in the study sites generally comprises of seven channels as follows:

1) Producers $>$ Retailer $>$ Local Consumers.

2) Producers $>$ Village Merchant $>$ Retailer $>$ Local Consumers.

3) Producers $>$ Village Merchant $>$ City Merchant $>$ Local Consumer.

4) Producers $>$ Village Merchant $>$ City Traders $>$ Wholesalers $>$ Local Consumers.

5) Producers $>$ Village Merchant $>$ City Traders $>$ Auction Market $>$ Wholesalers $>$ Exporters $>$ Consumers.

6) Producers $>$ Village Merchant $>$ City Traders $>$ Auction Market $>$ Processing Companies $>$ Exporters $>$ Consumers.

7) Producers $>$ Informal Traders $>$ Export $>$ Consumers.

\subsubsection{Actors, Functions and Characteristics}

Producers: The producers also known as collectors are the first actors in the chain. Their main functions are to manage, tap trees, collect, pack and deliver the product either to village merchant or to a point of sale (primary, secondary markets or informal trade). Based on the focus group discussion in Mefaza and Hawata, it was revealed that a producer cannot sell in the secondary or terminal markets if the amount of gum is less than 4 kantar. This was mainly because the price he will obtain in these markets will be affected by the levies imposed at the markets. Hence, he sells to the village merchants or to the intermediaries. This necessitates the formulation of some kind of associations or cooperatives to help small producers to sell their products at fair prices.

Marketing of gum Arabic is a seasonal activity, and the peak of it does not coincide with farming season in the region. After completing the harvesting of their field crops and tapping activities (October-November), farmers normally become engaged in gum and other crops marketing. The peak season for gum Arabic marketing starts from December to March each year. This implies that the producers get off-farm activities providing them with high income and hence enhance their standard of living.

Producer's cooperatives: Beside individual producers there are a number of producers cooperatives established by FNC. Their main functions are to overcome marketing problems and make producers more involved in gum production and marketing and to increase their market shares. There are 36 gum Arabic producers cooperatives (GAPC) including about 2338 members, organized under a so-called Gum Arabic Producers Association (GAPA). GAPC is a multi-purpose joint liability group of members based on common trust. The cooperatives and the association was established in 1993 with support from the multi-donor Gum Arabic Belt Restocking Project and the FNC to promote self-reliance using native Sudanese concepts such as community-based frameworks with revolving funds or "sanduq". Currently, these cooperatives are not functioning at the project sites.

The GAPA functions include administration of the credit activities concerning price negotiation, credit deli- 
very and repayment collection; supervision of the inputs delivery and distribution systems, including the drinking water distribution; participation in several village school development activities.

Traders: The majority of gum Arabic traders are city traders, gum companies, wholesalers followed by intermediaries. The major functions of this segment is selling, cleaning, re-packing and storing of the produce. According to key informants the number of traders is very few; there are 3 - 4 gum traders in Hawata, and Galel Nahal, 2 - 3 in Bazora and Doka and about 6 - 8 in Gedarif. The ages of these traders' ranges from 35 to 70 years. There is only one wholesaler for gum in Gedarif market who buys and sells in large quantities. This wholesaler buys from the producers, village merchant, city merchants, and intermediaries and from the auction market in Gedarif city. He sells either to big processing companies in Gedarif or to exporters. According to key informants all gum traded in the auction market is regularly bought by this wholesaler, who stockpiles and stores the products waiting for the prices to increase or for export.

Gum companies: There are six privately own gum companies in Gedarif town (Table 4) where gum is further cleaned, sorted into different grades. These companies employ between 20 - 30 employees on temporary basis to clean and grade gum before packing for export or domestic market. The majority of these are generally poor household females.

Informal traders "smugglers": These are group of risk-taker traders who often buy gum from producers and sell across the borders. Gum smuggling is common in the region, based on key informants producers in Bazora quite often sell their produce to traders who commonly export it to Ethiopia, Eretria and the Democratic Republic of Congo. Gum smuggling was mainly attributed to the high prices paid by those traders and the high taxes and levies imposed on gum by the different local authorities. Generally, the floor prices are very low and in most cases do not cover production costs. For example, at the time of study (February, 2012) the floor price for gum amount to 400 SDG/Kantar, and smugglers pay more than 600 SDG/Kantar to the producers at farm gate.

Intermediaries (middlemen): These either work privately or are agents (Wakeel) for some traders or companies. They purchase gum Arabic directly from producers, village merchants or city merchants and sell to wholesalers or in the auction market. Their funds for purchases are either bank loans or the sale of animals or cash crops, if they run their own business. If they are agents working for traders and/or companies, they buy gum for these entities and receive commission.

Retailers: These are road-side buy-and-sell traders (petty traders) who trade in different commodities. They normally buy in small quantities and sell in very small quantities directly to household consumers. In big town like Hawata and Gedarif the retailers sell gum to local consumers at a price of 20 SDG per kg. Gum retailers comprises of men, women, boys and girls of different age and education.

Exporters: There are no exporters in the East Region. Normally, exporters reside in big cities such as Port Sudan and Khartoum who normally have agents in the production sites. Exporters had their entry capital into gum Arabic business from different sources such as loans from banks or own business.

\subsubsection{Value Addition}

Value-addition is value increase due to processing and is measured in percentage increase in value from one given stage to another stage [25]. The author further maintains that the level of processing is not always proportional to value increase as in the case of some products (e.g. Agar wood) where level of agar wood processing appears to be inversely related to value increase. For this product, the largest value-increases are seen in the high value chain with no transformation of raw material, and the lowest value increase in low value chains with several stages of transformation [25].

Table 5 shows estimated costs and margins for the main actors in the gum chain in the study sites, using the

Table 4. Gum Arabic companies in Gedarif.

\begin{tabular}{ccc}
\hline & Company Name & \multicolumn{1}{c}{ Functions } \\
\hline 1 & Worm Sea Company & Buy, clean, sorting and sell \\
2 & El Sharij Company & Buy, clean, sorting and sell \\
3 & Khidir Enterprise & Buy, clean, sorting and sell \\
4 & Osama Abdalla Hamad & Buy, clean, sorting and sell \\
5 & Kassala Company & Buy, clean, sorting and sell \\
6 & El Rreifabi & Buy, clean, grade, powdering and sell \\
\hline
\end{tabular}


Table 5. Estimates of costs and margins for the main actors in gum Arabic chain at Hawata market (February, 2013).

\begin{tabular}{ccc}
\hline Chain actors & & SDG/kantar \\
\hline Producer & Production cost & 250 \\
& Sale price (village merchant) & 300 \\
Village merchant & Gross margin & $\mathbf{5 0}$ \\
& Purchase price & 300 \\
City merchant & Transport cost & 2 \\
& Sale price (city merchant) & 380 \\
& Gross profit & $\mathbf{7 8}$ \\
& Purchase price & 380 \\
& FNC levy & 5 \\
& Market fees & 2.5 \\
& Gum Arabic union levy & 1 \\
& Zakat (10\% from sale price) & 40 \\
& Other costs & 1
\end{tabular}

long channel. The analysis of gum prices and associated costs were made for producers in Hawata market where gum is locally traded. As shown in the table the producers incur an average cost of 250 SDG/kantar and sell to village traders at 300 SDG/ kantar, making a margin of 50 SDG per kantar. The village traders incurs a transportation cost of 2 SDG per kantar, sell to city merchant at price of 380 SDG and earns a margin of 78 SDG/ kantar. A city merchant in Hawata market incurs different costs (market fees and levies) amounted to 49.5 SDG/kantar, and sells at Gedarif market at a price of 500 SDG/kantar and earns a margin of 120.5 SDG/kantar. The total value added in the process is 248.5 SDG/kantar.

The results clearly demonstrate the upward skewed benefit distribution among the value chain actors. The total relative commercialization margin was $80 \%$ indicating that the actors involved in marketing of the product accrued higher proportion of the end market price, while those involved in the production activities "producers”, receive less income counting about $20 \%$ of the end market price. However, the margin for producer who sells to informal traders (short channel) amounts to 250 SDG/kantar, which is almost five times what he gets (50 SDG/kantar), if he sells using the long channel. The results establish that gum Arabic production and marketing is financially profitable for producers and traders (village traders and urban merchants), however, gum producers receive less income. Technical, financial, and institutional support could result in an increase in local actors' income and contribute to sustainability of the supply of the commodity.

The present marketing system can be changed through simple interventions that promise to substantially increase return to the producers. Several links in the marketing chain can be eliminated by organizing the producers into group and facilitating the value addition and marketing of the produce. The simple value adding steps are: first by grading the produce, the second provision and enhancement of storage capacity, and third, by provision of micro-finance, so that farmers cannot sale when prices are low and to avoid distress selling and traders exploitation.

Gum Arabic is generally used as an additive which represents a small portion of the cost of the finished product. It is regarded by end users as having technical advantages which makes it difficult to replace completely in many applications. This makes demand for gum price inelastic; supply is the key factor on the demand side. Value addition is understood as value increase due to processing. It is measured in percentage increase in value from one given stage to another. For gum Arabic the major proportion of value resides at the retail stage (abroad). Hence, grading and differentiating the products into consumable and commercial products is an essential step as this is where consumers show their preferences. 


\subsubsection{Constraints and Opportunities to Entry and Growth}

Several constraints discouraged the local communities to engage in gum Arabic production and marketing in the study sites. The results from the study reveal that poor land security, one-sided prices, taxes and levies, lack of finance and appropriate skills are major impediments to gum commodity growth and development. Some of these constraints were reported in Borno State in Nigeria [26].

1) Constraints

$>$ Poor access and insecure rights to land discourage small producers from producing the commodity on sustainable basis.

> Unattractive and fluctuating local prices are key constraint to small producers and have negative implications on sustainability of gum supply. This can be surmounted by setting producer's prices proportional to that of international market prices.

$>$ Limited access to finance. Access to finance will help new firms expand if successful.

$>$ Access to market information and uneven power to market entry. Gum Arabic market in the region is dominated by large marketers. There is a high inequality in income distribution among the gum Arabic chain actors in the region. Floor price for gum Arabic is too little and distract producers from tapping gum trees. These factors combined might have detrimental impacts on the gum supply and can be overcome by organizing producers in cooperatives.

$>$ Limited processing is one of the main barriers in industrialization and marketing of gum Arabic in the near future. This barrier can be overcome by introduction of more advanced processing facilities.

$>$ Smuggling: Smuggling of gum Arabic outside the region is rampant and has significant negative impact on gum supply. The main causes are the increased taxes and levies on the produce. Complete removal or reduction of these levies would help small producers to get share in the market.

$>$ Tapping Skill: Most of gum tapping in the study area is carried out by tappers from outside the region. Producers in the project sites have limited skills in gum tapping, especially for A. seyal. This has resulted in obtaining low yields from this species.

2) Opportunities

$>$ Gum Arabic by definition is natural organic product and thus well-fit for fair trade, environmentally sustainable and organic market development.

$>$ As natural organic product, gum Arabic has a high international demand.

$>$ Existence of market and marketing experience. Assessment of the market structure of gum Arabic in the region indicated that gum marketing in the region has long been practiced by a great number of traders. One trader at Hawata market has over 50 years and above experience in the business.

> Willingness of the local communities to involve in production and marketing.

$>$ Cooperation to pool raw gum by organizing producers into groups will offer an opportunity for income generation, expansion of production area and supply.

$>$ Processing of raw gum into its commercial products requires equipment and technologies, these are now available in Gedarif City (1 processing plant). The introduction of more advanced processing could potentially provide good employment opportunities for local households (especially women) to benefit from processing stage of the product.

$>$ Good and accessible all season road to port of exportation.

$>$ New proposed policy regulations that ensures the provision of stable annual supply of the product to help stabilize the international markets.

These factors are likely to have a positive impact on gum Arabic production and marketing in the coming years. Sudan has historically been a major exporter of gum Arabic to the world market, but price supports play a large role in keeping Sudan gum competitive. From a global standpoint, therefore any subsidies on production and marketing would be expected to have a positive impact on exports and trade.

\subsubsection{Opportunities for Value Addition, Supply Chain, Distribution Synergies and Gender-Specific Development}

Numerous opportunities exist in the region for value addition and distribution synergies and gender-specific development, include:

Increased domestic consumption as a result of increased use of gum Arabic by local industry (Soft drink and sweet). 
$>$ Increased number of processing companies in the region.

$>$ Generate jobs opportunities especially for women

$>$ Diversify the region's national and foreign exchange earnings

$>$ Gum has high synergy with natural resource management and other sectors.

$>$ Gum has high synergy with private sectors for enhancing regional and national growth.

\subsubsection{SOWT Analysis}

1) Strengths

- The commodity has multiple values and functions, including provision of fodder for livestock production, wood for charcoal and carbon sequestration. This can encourage improved integrated management as a climate change adaptation mechanism, an endeavour that several donors are interested in and seeking to pursue.

- The importance of the commodity to rural livelihoods development and enhancement of environmental quality is stimulating increased involvement by the government as well as development partners such as NGOs in supporting local efforts and national and/or regional government initiatives for improved management and exploitation of the commodity.

- The integration of gum producing species as a major component in land use management for gum Arabic production and environmental sustainability, if done properly can allow the country to comply with the international agreements it has signed, such as the FCCC, CBC and CCD.

- Economic remunerations from the gum Arabic are attracting private sectors investment in gum processing and trading.

- The country has an efficient loan provision system and availability of credit for those interested in investing in the gum production.

- The gum Arabic sector has potential to attract research and development efforts at various scales.

- New proposed Gum Policy.

2) Weaknesses

- Unclear and ill-defined access rights and ownership to land in the study sites could lead to unsustainable supply and irresponsible exploitation and resource degradation.

- Poor handling and lack of quality control are likely to be obstacles to improved and sustainable marketing.

- Lack of value-added processing that weakens producers' income gain from the commodity.

- Limited involvement of Mechanized farmers in the planting, management and protection of the resource base.

- Limited tapping skill among the local producers and dependence on skilled tapers from outside the region. 3) Opportunities

- Improved policy reforms and appreciation of the contribution of the commodity to rural livelihoods and the national economy and their potential in sustainable land management, which has been incorporated into the country current National Comprehensive Strategy (NCS), National Forest Policy (NFP), Gum Arabic Policy Notes (GAPN) as well as several international conventions ratified by the government such as Action Plan for Desertification Control, National Plan of Action (NAPA), Convention on Biodiversity (CBC).

- Large body of scientific research regarding biology, silviculture, eco-physiology of the gum producing tree species in pure or intercropped combination (ARC).

- Strong and growing market demand at local and international levels. Growing consumer interest in organic/ natural products is boosting demand for gum product from Sudan.

- Extraction of gums is not destructive to the tree and the ecosystem can also benefit from other global opportunities such as Carbon Trade, using the reduced emission from deforestation and degradation mechanism (REDD).

- Value-added processing is possible and will boost returns from the commodity.

- The policy of private sector-driven development in the country and the growing involvement by private entrepreneurs in the commodity that boosted production and trade.

- Encouragement and mobilization of large-scale mechanized farmers can help large-scale management or/ exploitation of commodity.

4) Threats

- Frequent drought and climatic changes will result in more denudation of vegetation cover. 
- Wild forest fires, wood fuel cutting, horizontal expansion of agriculture reduce the area under tree cover.

- Improper tapping tools and techniques (Axes and Harba) will damage trees and reduce their production potential.

- The area is under intensive grazing by large number of livestock.

- Intentional wounding of trees by herders and improper wounding of trees by local collectors will reduce the productive cycle of trees.

- Conflicting policies, programmes and strategies, regarding land use and resettlement, construction, and economic and rural development policies.

- Multiple taxes levied by different authorities.

- Low financial and technical capacity of most producers currently involved in the commodity, particularly with regard to value added processing and large-scale development activities.

- Population growth and associated migration to the region in search of livelihoods.

- On-going land and environmental degradation in the project sites that necessitates large-scale resettlement programmes.

\subsubsection{Potentials and Constraints for Gum Arabic Production}

Gum Arabic production in the study sites has many potentials and encountered a number of constraints (Table 6).

\subsubsection{Proposed Interventions}

The market of gum Arabic in the region by and large is imperfect [27] [28]. The producers do not get a fair return for their produce. Traders on the other hand have dominant position in the marketing at the secondary and terminal markets levels. This situation conforms to that reported in Kenya [29] and in Nigeria [26]. The present production and marketing systems can be changed through simple interventions:

$\checkmark$ Promote provision of political and logistical support through adoption of the State Government Action Plan (Legal and Executive).

$\checkmark$ Promote active participation of targeted groups (individuals and communities) through their formal and informal institutions.

$\checkmark$ Active participation of local, provincial governments and other local committees.

$\checkmark$ Promote participation of related Corporations and Administrations and development projects involved in afforestation activities.

$\checkmark$ Up scale production and expand resource base through plantation and agroforestry.

$\checkmark$ Increase community awareness and enforce laws to protect the gum Arabic trees.

$\checkmark$ Organize producers in order to overcome the current weak trading structure and to improve services provided to them so that they can produce according to market requirements.

$\checkmark$ Increase access to credit and funds.

$\checkmark$ Provision of soft loans.

Table 6. Potentials and constraints to gum Arabic production.

\section{Constraints}

Availability of gum Arabic producing trees (Hashab and Taleh).

$>$ Conducive climatic conditions for tree growth and gum production.

$>$ Available land to establish and expand the plantation.

$>$ Willingness of the local producers to involve in tree planting and gum collection.

$>$ High demand for the product in the local and international market.

$>$ The establishment of the gum Arabic Council Governance Institution.

$>$ Gum Arabic is part of the tri-partite economic programme the government depends on economic reform, export development, and enhancement of Sudan's economy.
$>$ Lack of land ownership by the local community

$>$ The decreased forest area due to traditional farming and encroachment of mechanized farming, overgrazing and burn resulted into loss of species and habitat destruction.

$>$ Limited availability of water and labor in the production zones.

$>$ Charcoal traders were another threat to the natural forests and marginal lands.

$>$ Floor price which encourages producers is not stable and fluctuating every season.

$>$ Lack of experience and poor working culture of the local people to harvest gum Arabic.

$>$ Over-grazing and woodcutting.

$>$ Production levies and fees imposed by the authorities obstructing production.

$>$ Smuggling gum to neighboring countries, due to the government insistence on imposing fees and levies on the commodity. 
$\checkmark$ Create a strong link between producers and traders with the view to cultivate, collect and market gum Arabic in a responsible manner and in a quality demanded by the market.

$\checkmark$ Community mobilization and behavioral change on work culture and entrepreneurship.

$\checkmark$ Establish linkage with local traders/investors working on gum Arabic production and export.

$\checkmark$ Skill building in gum Arabic tree management and harvesting.

$\checkmark$ Establish and promote gum Arabic collectors cooperatives/associations in potential areas (business skill, management).

\section{Conclusions and Recommendations}

In the study sites, gum Arabic based enterprises offer good prospects for enhancing the livelihood and income of local communities. However, the development of an enterprise fulfilling environmental, market and legal requirements can only be facilitated through value chain analysis. Based on the value chain assessment, gum has the potential to open new markets and bring new opportunities to smallholder farmers. The project sites are very rich in terms of gum Arabic trees species (A. senegal and A. seyal) that have the potential to bring income and change peoples' lives. There is no competition for these trees which are of high value and will improve livelihoods as well as generate new sources of income.

The study has shown that there is a potential for high gum Arabic production in the study sites. This mainly could be attributed to the larger resource-base of high population of A. senegal and A. seyal trees; the willingness of the local communities to engage in fulltime gum collection and available market. Nevertheless, numerous constraints need to be addressed to make gum Arabic production an attractive undertaking to the local communities. Key among them are: lack of land ownership by the local communities; unstable and fluctuating floor price every season; limited availability of water and labor in the production zones; lack of experience and poor working culture of the local people to tap and harvest gum Arabic; production levies and fees imposed by the local authorities obstructing production and sustainability of supply.

These problems can be addressed through securing land tenure; creation of producers associations in order to overcome the current weak trading structure and to improve services provided to them so that they can produce according to market requirements; creation of public awareness about the international trends of the commodity prices to make the producers understand that the amount being offered at any given time is in agreement with global market prices trends; creation of a strong link between producers and traders with the view to cultivate, collect and market gum Arabic in a responsible manner and in a quality demanded by the market, provision of training to build producers capacities and skills in regard to gum tapping and collection, provisions of drinking water and other essential service. Moreover, the production levies and taxes imposed on the commodity should be reduced or removed completely. Additionally, the infrastructure needs to be developed and/or improved to ease the problem of accessing the gum producing zones by potential buyers to create a link between collectors and buyers. There is an urgent need to strengthen the capacity and ability of gum producers and other stakeholders to produce, collect and market high quantities of good quality of gum Arabic in order to increase income, create jobs and diversify the region foreign exchange earnings.

\section{Acknowledgements}

This paper is an output from a consultancy report prepared by the author and funded by IUCN Eastern and Southern African Regional Office (EASARO) under Contract No. ESARO/77174-030/1448 "Economic valuation and market chain analysis for selected products from Agroforestry systems". The views expressed in this paper are not necessarily those of ESARO/77174-030/1448. The authors acknowledge the research assistance of IUCN/ESARO. The authors are indebted to Mr. Mahmoud Awad Mekki for his cooperation during the field work and data analysis. The assistance received from the Project staff at El Fau, Hawata and Gedarif is highly appreciated.

\section{References}

[1] Kaplinsky, R. and Morris, M. (2000) A Handbook for Value Chain Research. IDRC. http://www.ids.ac.uk/ids/global/pdfs/VchNov01.pdf

[2] FAO (2004) Commodity Chains for Pro-Poor Rural Growth. Operational Guidelines, Rome. 
[3] UNIDO (2011) Pro-Poor Value Chain Development: 25 Guiding Questions for Designing and Implementing Agroindustry Projects. United Nations Industrial Development Organization (UNIDO), Vienna.

[4] Lecup, I. and Nicholson, K. (2009) Community-Based Tree and Forest Products Enterprises: Market Analysis and Development. FAO, Rome.

[5] Lusby, F. And Panlibuton, H. (2007) Value Chain Program Design: Promoting Market-Based Solutions for MSME and Industry Competitiveness. Office of Microenterprise Development, Said/G/Egad/MD, Washington DC.

[6] Humphrey, J. and Navas-Alemán, L. (2010) Value Chains, Donor Interventions, and Poverty Reduction: A Review of Donor Practice. IDS Research Report 63, Brighton.

[7] Stoian, D., Donovan, J., Fisk, J. and Muldoon, M. (2012) Value Chain Development for Rural Poverty Reduction: A Reality Check and a Warning. Enterprise Development and Microfinance, 23, 54-69. http://dx.doi.org/10.3362/1755-1986.2012.006

[8] Donovan, J., Cunha, M., Franzel, S., Gyau, A. and Mithöfer, D. (2013) Guides for Value Chain Development-A Comparative Review. CTA \& World Agroforestry Centre, Wageningen.

[9] Staritz, C. (2012) Value Chains for Development: Potentials and Limitations of Global Value Chain Approaches in Donor Interventions. Austrian Research Foundation for International Development, Vienna.

[10] Bammann, H. (2007) Participatory Value Chain Analysis for Improved Farmer Incomes, Employment Opportunities and Food Security. Pacific Economic Bulletin, 22, 113-125.

[11] Eltayeb, G. and Osman, H.M.E.M. (2011) Land Tenure and Baseline Study for the Project: Securing Rights and Restoring Lands for Improved Livelihoods Kassala and Gedaref States-Sudan (Final Report).

[12] JECFA, Joint FAO/WHO Expert Committee on Food Additives (1997) Supersedes Specifications Prepared at the 49th JECFA, 1997. Published in FNP 52 Add 5 (1997). C.A.S. No. 9000-01-5. http://www.fao.org/ag/agn/jecfa-additives/specs/Monograph1/

[13] Couteaudie, T.Y. (2007) Export Marketing of Sudanese Gum Arabic. SUDAN MULTI-Donor Trust Funds, MDTFNational, Sector Policy Note, Multi Donor Trust Fund-National Technical Secretariat, the World Bank, Khartoum.

[14] GAC, Gum Arabic Company (1996) Paper Presented on Problems and Constraints of Marketing Gum Arabic. Gum Arabic Conference, Friendship Hall (19 October 1996), Department of Research and Statistics, Gum Arabic Company, Paper No. 9/96, Khartoum, Sudan, 8.

[15] Forman, S. (2102) Revitalizing the Sudan Gum Arabic Production and Marketing. P110588-Report on Implementation Status and Results. Report No. ISR8088.

[16] Mahmoud, T.E. (2004) The Adequacy of Price Incentives on Production, Processing and Marketing of Gum Arabic in Sudan. A Case of North and West Kordofan. PhD Thesis, TU Dresden, Dresden.

[17] Taha, M.E. (2006) The Socio-Economic Role of Acacia Senegal in Sustainable Development of Rural Areas in the Gum Belt of the Sudan. PhD Thesis, TU Dresden, Dresden.

[18] Karama, M.M. (2001) Gum Arabic: Present Situation and Future Prospects. Department of Research and Statistics, Gum Arabic Company, Paper No. 3/01, Khartoum, 13.

[19] Khalid, A.M. (2005) Annual Reports and Archive Unit. Note No. 28-2005, Ministry of Finance, North Kordofan State, 17.

[20] Martin, B., Wayland, G. and Werner, S. (1987) Economics. 2nd Edition, Houghton Mifflin Company, Boston.

[21] Schrekenberg, K., Marshal, E., Newton, A., Velde, D., Rushton, J. and Edouard, F. (2006) Commercialization of NonTimber Forest Products: What Determines Success? Forestry Briefing. Overseas Development Institute, London, 6 p.

[22] Markin, J. (1982) Marketing Strategy and Management. 2nd Edition, John Wiley and Sons, Hoboken.

[23] Tieguhong, J.C. and Ndoye, O. (2004) Development of Trade and Marketing of NTFP for Poverty Alleviation in Africa. CIFOR, Yaounde, 48 p.

[24] Tieguhong, J.C. and Ndoye, O. (2006) Transforming Subsistence Products to Propellers of Sustainable Rural Development: Non-Timber Forest Products (NTFPs) Production and Trade in Cameroon. In: Wohlmuth, K., Burger, P., Gutowski, A., Hussain, M.N., Kneduk, T. and Meyn, M., Eds., Africa-Escaping the Primary Commodities Dilemma, African Development Perspective Yearbook, Vol. 11, Unit 1, Lit Verlag, Berlin, 107-138.

[25] Jensen, A. (2009) Valuation of Non-Timber Forest Products Value Chains. Forest Policy and Economics, 11, 34-41. http://dx.doi.org/10.1016/j.forpol.2008.08.002

[26] Gwary, M.M., Donye, A.O., Wakawa, R.C. and Shallangwa, M.D. (2013) Constraints to Extension Service Delivery in the Production, Processing and Marketing of Gum Arabic in Magumeri Local Government Area of Borno State, Nigeria. Agriculture and Biology Journal of North America, 4, 126-131.

[27] Velde, D.W., Marshall, E., Newton, A. and Schrenkenberg, K. (2004) Successful NTFP Commercialization. A Quan- 
titative Analysis Based on Household and Trader Level Data. UNEP-WCMC and ODI Report, 94 p.

[28] Tieguhong J.C., Ndoye O., Tchatat, M. and Chikamai, B. (2009) Processing and Marketing of Non-Wood Forest Products for Poverty Alleviation in Africa. Discovery and Innovation, 21, 60-65.

[29] Wekesaa, C., Luvandaa, A.M., Mugaa, M.O., Chikamaia, B.N. and Makenzib, P.M. (2013) Market Chain Analysis of Gum Arabic Trade in Kenya. Octa Journal of Environmental Research, 1, 93-106.

http://www.sciencebeingjournal.com 